\title{
Story as Pedagogy: A Reflective Commentary
}

\author{
Corrine Glesne and Marleen C. Pugach
}

\begin{abstract}
This commentary seeks to encourage reflection upon learning and teaching through story. The authors illustrate ways they have used story in their teaching and what they perceive as the benefits of doing so. They explore how they learned through narrative as children and why they came to value it as a way of seeing and thinking. Then they consider how story disciplined their approaches to professional work before identifying specific narrative strategies used in teaching undergraduate and graduate students. The article concludes with suggestions about ways to better integrate narrative practices into teaching and learning.
\end{abstract}

\section{Background}

Stories convey lessons, messages, and perspectives. They evoke feelings, create empathy, trigger tears, and arouse rage. They provide frameworks for finding meaning in lives and the world. And they can help shape beliefs and actions that are inclusive and supporting or exclusive and destructive. Through this commentary, we strive to encourage readers to reflect upon how they learn and teach through story and to think consciously about the potentially positive roles of story as pedagogy.

Everyone's life is shaped by the narratives of the places and times in which they live and by the stories told to make sense of experiences. Through our comments, we (two retired professors) strive to illustrate some of the ways we have used story in our teaching and what we perceive to have been some of the benefits of doing so. This is a reflective essay, taking a personal approach and drawing upon our own stories_-from three vantage points_as examples.

First, we challenged ourselves to think about how we learned through narrative and why we came to value it as a way of seeing and thinking - a value that predated our commitments to narrative in our professional lives as educators. Next, we considered how narrative disciplined our approaches to professional work, starting with graduate studies. Last, we identified specific strategies we used in teaching undergraduate and graduate students that drew directly on the power of narrative. In sharing our stories, we seek to support and strengthen other educators' commitment to using narrative, not to simply enrich, but rather as foundational to the development and growth of students. 


\section{Story and Our Personal Development}

Early in the process of writing this commentary, we discussed our attraction to story and gave ourselves the assignment of writing independently about the place of story in our own personal development. By highlighting the words and phrases that stood out in our individual reflections, we created the following transcription of the essences of this writing. We acknowledge as an important theme the circumstances that, first of all, allowed us to spend much of our childhoods reading and writing, and also provided us with access to books, along with the encouragement of a parent or teacher.

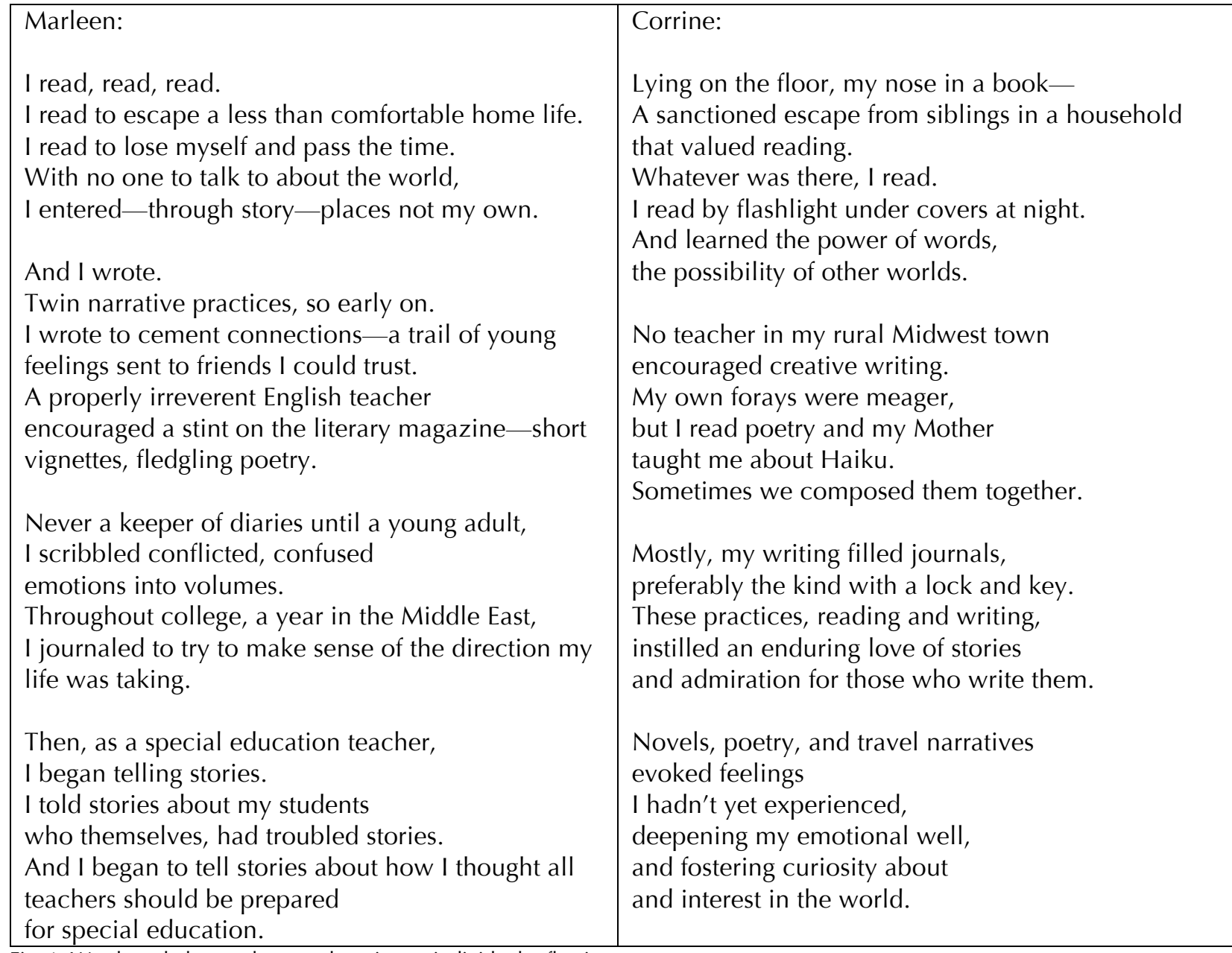

Fig. 1: Words and phrases that stood out in our individual reflections

Whether growing up in a metropolitan suburb (Marleen) or a small rural town (Corrine), reading and writing-twin narrative practices-were key to our early connections to story. Fortunate to have easy access to books, we both read insatiably. Although at first reading provided escape from aspects of home life, it became reinforcing as we learned about lives and worlds beyond our own. Then, encouraged by a teacher or a parent, we tested out, to varying extents, aspects of creative writing. Much of our early writing explored our own "conflicted, confused emotions," whether secreted away in journals or scripted to friends in letters. These writings also held dreams and plans-stories of how we wanted life to be. Through reading and writing, we both were sensitized early on to the value of story. We could have been 
exposed to narrative in other ways, for example, by family practices like oral storytelling. Ours was mostly more private, but our orientation towards story influenced our paths as professionals.

\section{Story, Graduate Studies, and Approaches to Professional Work}

Reading a novel after reading semiotic theory was like jogging empty-handed after jogging with hand weights. What exquisite guilt she felt, wickedly enjoying narrative! Madeleine felt safe with a nineteenth century novel. There were going to be people in it. Something was going to happen to them in a place resembling the world. (Eugenides, 2011, p. 47)

Different paths converged, taking us to graduate school at the same place and same time. Between her bachelor's degree in anthropology and beginning graduate school, Corrine lived and worked in other parts of the world for much of six years. She knew anthropologists kept field logs and journals, and as she traveled she did as well, documenting what she saw and did and learned. Journal keeping and working in other cultures prepared her to gravitate towards ethnographic and qualitative inquiry in graduate school. Marleen became an elementary school teacher, specifically a special education teacher. "I never wrote about my elementary school teaching," she states, "but I thought about my work narratively. No surprise, I was drawn to qualitative methodology as a doctoral student although no one else in my specific program used_or was particularly interested in—those research methods."

Because we already inclined toward story in our personal and professional lives, our landing at the University of Illinois' College of Education in the late 1970s was fortuitous. An early adopter of the qualitative research paradigm, the Center for Instructional Research and Evaluation (CIRCE), at that time, simmered with creative professors doing innovative work, several of whom (Alan Peshkin, Terry Denny, and Robert Stake) became guides and mentors for our work as graduate students. From them, we learned not only about qualitative inquiry, but also about the possibilities of writing and storytelling and grew to value story as a way to communicate research results. We participated in what fondly became known as the "Fat Data Group," an informal collective of half a dozen doctoral students studying with Alan Peshkin. We met regularly to share our developing projects (Peshkin included), asking the group for insight and suggestions on anything from interview questions to editing. We learned to trust the group to provide helpful perspective, supportive feedback, and the political will to carry on with this approach to research.

Through these teachers and our own research, we learned to listen for multiple perspectives and to seek complexity. The narrative approaches we embraced included being empathetic to another's story and also listening critically, placing the story in a socio-cultural and historical milieu-although we understood it was never possible to do so completely or perfectly. That kind of teaching and learning made sense. We didn't realize what a methodological oasis we had happened upon, finding support and encouragement at a time when qualitative research was not routinely accepted in much of the larger educational research community.

As we entered into teaching in universities-Marleen in Milwaukee and Corrine in Vermont-story took on a central role as an organizing principle for our work. A professor of teacher education in urban 
communities, Marleen prepared novices for positions in urban elementary and middle schools. She realized she had strived to tell a couple of interrelated stories across her career. The first storyone that no one else seemed particularly interested in telling at the time-was how the preparation of every teacher was being shortchanged by too narrowly defining the work of special education teachers, and how understandings of diversity were also being shortchanged by separating special education from growing commitments to multicultural education. She began to tell this story in her professional writing as well as in academic venues. Alongside this central organizing story, she was trying to help studentswho were often completely unfamiliar with working in urban schools-engage well with the children and youth in their inner-city clinical school sites. She asked these teacher candidates to learn the stories of their students, particularly the compelling stories of students whose backgrounds differed from theirs.

Corrine primarily taught qualitative research, anthropology of education, and social foundations of education courses. With a commitment to honoring multiple perspectives, multiple values, and multiple ways of living, qualitative inquiry became her vehicle for entering into teaching-not through whatever the current academic jargon and theoretical fads were-but through story, through listening to her students' stories of their lives and through teaching them how to seek out and make sense of the stories of others.

Albeit employed in somewhat different ways, narrative knowing shaped our work. We both used teaching strategies that reflected our commitment to the value of story in learning.

\section{Narrative and Teaching Strategies}

Over the years, we used six pedagogical strategies embedded within our commitment to story. We supported each other's implementation of these strategies in our distant efforts as well-a community of two, anchoring the importance of story within our "teacher talk."

\section{Reading Published Narratives}

In anthropology and social foundations of education classes, Corrine assigned published novels, autobiographies, and poetry to immerse students in the lives of people with experiences and histories different from their own. These texts provided insights and a basis for conversation connected to the course content (see, for example, Ambiguous Adventure by Cheikh Hamidou Kane, a classic novel on colonization and the clash of Islamic African values with Western schooling in colonial French Senegal). We both used ethnographies in our qualitative research courses to exemplify authors whose writing from data was exceptional in its use of varied creative approaches, as well as to introduce content that we felt important for our students to consider (Barbara Myerhoff's Number Our Days: Culture and Community Among Elderly Jews in an American Ghetto is another classic and a favorite of ours). 


\section{Listening to Stories of Others}

We asked our students to talk with and learn from the stories of others. We both tended to focus on difference in these assignments. For example, in undergraduate teacher education courses, Marleen and her colleagues required a "two-way autobiography," asking candidates to work with students whose background differed from their own. This typically meant white candidates worked with Black, Latino, Hmong, or Native American students. Each teacher candidate paired with a student over several sessions, sharing back and forth from an interview protocol. In this context of dual disclosure, candidates learned about their students' lives—and came back with stories of their own fledgling-and often naïvediscoveries from these stories, such as seeing the value in a large extended Latino family living together. These same teacher candidates were also required to work in an adult learning setting with those whose background differed from theirs. In these settings, they learned stories, for example, of adults coming to citizenship or English classes at night, after a full day of low-paying work, always talking about what it meant for their children's futures. These story-featuring learning opportunities were designed specifically to create empathy and disrupt students' (often negative or stereotypical) views of families in Milwaukee's urban, inner core.

\section{Creating Better Writers}

Our experiences with the "Fat Data Group" gave us confidence in the value of reading and commenting on each other's writing-even (and sometimes especially) in its most "drafty" stages. We had not done that before our graduate school experience and we later found that most of our doctoral students had never done so either-the exception being the few with English degrees or who had previously attended creative writing classes where "workshopping" other's writing was common. A palpable sense of foreboding accompanied the sharing of the first few pages. But invariably, students got over it and immediately embraced the value of feedback, guided by clear guidelines for reading and supportive commenting on manuscripts.

Learning the value of sharing work with others for constructive feedback, students sometimes asked to continue the process when the class ended. Whether this resulted in a writing group or in mentor/mentee sessions, we grew in relationship to each other through the process of sharing our writing.

\section{Writing Self-Stories}

We asked students to write autobiographically and to share their writing with classmates. Sometimes we used poetic guidelines for these self-stories, sometimes prose. Through these strategies, we heard diverse stories such as those of first-generation graduate students from Hmong families who unequivocally considered themselves to be political refugees, but whose parents and grandparents never talked about their experiences during the Vietnam War; of a trans student who used this assignment as an opportunity to come out to the class-well before most people were talking about the deep difficulties of being trans in our society; of the son of migrant farmers, who himself had been a migrant worker, pursuing his doctorate; or of native Vermonters whose grandparents had to deny their Abenaki heritage to escape 
discrimination. Through this approach to narrative, students shared perspectives and challenges they might otherwise not have shared or may have shared only one-on-one. Their contributions deepened the classroom community.

We also sometimes asked students to write some aspect of their own story as it related to specific course content, such as first realizations of race and racism while, in class, deconstructing the concept of race. In addition to new realizations and insights, students wrote in a personal voice, beginning to let go of the stilted, often obtuse, formal language they associated with academia. When encouraged to write about what they knew-their own life or their parents' lives-they began to thrive as writers.

\section{Using Creative Writing Techniques}

In addition to autobiographic poems, we ventured into other forms of creative writing in our research courses as a way to think about and present data. For example, in a course focused on analyzing and writing up qualitative research data, Corrine asked students to consider their data from four different analytical frameworks: thematic analysis, autoethnography, poetic transcription, and ethnodrama. The class focused on these approaches one at a time, reading theory and practical advice as well as examples. For each approach, students (and sometimes Corrine) composed five pages of text from their data that was subsequently workshopped in class. Students discussed what they learned differently about their data through each approach-how thinking about and writing up their data in these various ways caused them to focus on different aspects of their data. Through engaging their creativity, students grew excited about their research and their writing, something some of them never thought possible. Several went on to publish articles from the work they began in that class.

\section{Giving Students Permission to Go Places They May Not Otherwise Have Gone, in Ways to Which They May Not Otherwise Have Had Access}

Finally, narrative research methods gave students interested in telling stories permission to do so in a disciplined, rigorous way. Not only were we privileged to assist students in telling evocative stories, but also we and other students learned from these shared narratives. An art teacher's dissertation illuminated the deep limitations of urban elementary school art programs where, for example, Kachina dolls made of toilet paper rolls were routinely considered appropriate projects. An African-American woman pursued narrative stories of African-American community college students who were successful in remedial mathematics programs (rather than the unsuccessful stories typically told). A young man working with people living with disabilities was able to join with his clients to together tell through his dissertation stories of disability and of people's strivings for control over decisions affecting their lives. These are but few examples among many that a narrative approach to learning and teaching has made possible in our classes. 


\section{Reflections and Possibilities}

We persisted in our individual and joint commitments to narrative as a way of organizing pedagogy because we liked what happened in our classrooms when we did so. What did the use of these particular narrative strategies mean for the quality of our teaching and learning?

First, the use of story (whether published or through students' interviews or writings) engaged students and shaped insights that would have been difficult to achieve any other way. Students connected to concepts and perspectives that may have been challenging or alienating if presented in other ways.

Next, narrative techniques created a sense of empathy and understanding among our students for individuals and communities with differing life circumstances. Students made personal connections to and grew curious about and interested in people, cultures, or situations that may not have concerned them before. As students worked to understand varying perspectives, we watched them develop in their understanding of complexity within social phenomena.

Further, narrative strategies often created a sense of community within the classroom. These strategies helped to build respect among participants, relationships, and sometimes, long-lasting friendships. By sharing their stories and the stories of others, students came to appreciate and value each other.

Finally, of particular delight to us as professors of qualitative inquiry, we saw students grow in enthusiasm and skill as researchers and writers. In writing their own stories or using creative techniques to write the stories of others, students often "found" their own voices and new passion.

We conclude with half a dozen ways to better integrate narrative practices into teaching and learning.

1. As teachers and citizens, we can work to provide all children with access to books that provide high-quality stories reflecting the diversity in our schools.

2. We can encourage students to write and, as teachers, provide constructive and encouraging comments. Schooling seems to mitigate against this with large class numbers and (for PK-12) obsessions with test preparation. But we can simultaneously argue against the class size and testing challenges - and be creative about ways to encourage writing-use of journals, short papers that add up to something longer, group processing of each other's writing, and so on.

3. We can encourage students to become better writers through group work and feedbackthe workshopping technique-providing them with guidelines for offering constructive, supportive reflections.

4. We can inform ourselves and encourage others to learn about qualitative inquiry and narrative ways of knowing.

5. We can be willing to mentor others in narrative ways of knowing and to continue to seek out mentors ourselves.

6. And, as teachers, we can consider story as a form of activism. We can use published narratives, we can write, and we can ask students to tell and write stories that communicate shortcomings, marginalization, and the need for change. 


\section{References}

Eugenides, J. (2011). The marriage plot. New York, NY: Farrar, Straus and Giroux.

Kane, C. H. (1961). Ambiguous adventure. Oxford, England: Heinemann.

Myerhoff, B. (1979). Number our days: Culture and community among elderly Jews in an American ghetto. New York, NY: Meridian.

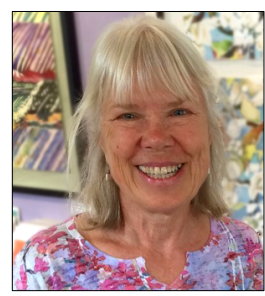

Corrine E. Glesne, PhD, is Professor Emeritus, University of Vermont (UVM). She is a qualitative researcher, educational anthropologist, and author of the text Becoming Qualitative Researchers (2016, 5th ed.), which has been translated into several different languages. She also authored The Exemplary Museum: Art and Academia (2013), as well as numerous other publications. Corrine has had extensive international experiences including directing a semester UVM program in Oaxaca, Mexico and teaching for seven years with the International Honors Program, a comparative educational program now affiliated with World Learning. Currently, she is pursuing interests in creative writing.

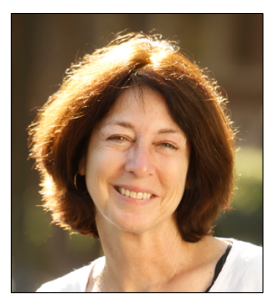

Marleen C. Pugach, PhD, is Professor Emeritus in the School of Education at the University of Wisconsin-Milwaukee. Her scholarly interests are focused on teacher education policy, practice, and reform at the intersection of general and special education; situating disability within the larger question of equity in the preparation of teachers; dual certification; and qualitative research methods. She is author of the introduction to teaching text Because Teaching Matters and the ethnographic study On the Border of Opportunity, as well as numerous articles, book chapters, and edited books. Marleen is a former Fulbright scholar and an international consultant on teacher education reform. 